\title{
Application of dead space fraction to titrate optimal positive end-expiratory pressure in an ARDS swine model
}

\author{
WEISHUAI BIAN ${ }^{1}$, WEI CHEN ${ }^{1}$, YANGONG CHAO ${ }^{2}$, LAN WANG $^{3}$, LIMING LI $^{2}$, \\ JIAN GUAN ${ }^{2}, X_{\text {XEFENG ZANG }}{ }^{1}$, JIE ZHEN ${ }^{1}$, BO SHENG ${ }^{1}$ and XI ZHU ${ }^{4}$ \\ ${ }^{1}$ Department of Critical Care Medicine, Beijing Shijitan Hospital, Capital Medical University, Beijing 100038; \\ ${ }^{2}$ Department of Critical Care Medicine, The First Affiliated Hospital, Tsing Hua University, Beijing 100016; \\ ${ }^{3}$ Department of Critical Care Medicine, Dongzhimen Chinese Medical Hospital, Beijing Chinese-Medical University, \\ Beijing 100700; ${ }^{4}$ Department of Critical Care Medicine, Third Hospital, Peking University, Beijing 100083, P.R. China
}

Received August 6, 2015; Accepted October 5, 2016

DOI: $10.3892 /$ etm.2017.4117

\begin{abstract}
This study aimed to apply the dead space fraction [ratio of dead space to tidal volume (VD/VT)] to titrate the optimal positive end-expiratory pressure (PEEP) in a swine model of acute respiratory distress syndrome (ARDS). Twelve swine models of ARDS were constructed. A lung recruitment maneuver was then conducted and the PEEP was set at $20 \mathrm{~cm} \mathrm{H}_{2} \mathrm{O}$. The PEEP was reduced by $2 \mathrm{~cm} \mathrm{H}_{2} \mathrm{O}$ every $10 \mathrm{~min}$ until $0 \mathrm{~cm} \mathrm{H}_{2} \mathrm{O}$ was reached, and VD/VT was measured after each decrement step. VD/VT was measured using single-breath analysis of $\mathrm{CO}_{2}$, and calculated from arterial $\mathrm{CO}_{2}$ partial pressure $\left(\mathrm{PaCO}_{2}\right)$ and mixed expired $\mathrm{CO}_{2}\left(\mathrm{PeCO}_{2}\right)$ using the following formula: VD/VT $=\left(\mathrm{PaCO}_{2}-\mathrm{PeCO}_{2}\right) / \mathrm{PaCO}_{2}$. The optimal PEEP was identified by the lowest VD/VT method. Respiration and hemodynamic parameters were recorded during the periods of pre-injury and injury, and at 4 and $2 \mathrm{~cm} \mathrm{H}_{2} \mathrm{O}$ below and above the optimal PEEP(Po). The optimal PEEP in this study was found to be $13.25 \pm 1.36 \mathrm{~cm} \mathrm{H}_{2} \mathrm{O}$. During the Po period, VD/VT decreased to a lower value $(0.44 \pm 0.08)$ compared with that during the injury period $(0.68 \pm 0.10)$ $(\mathrm{P}<0.05)$, while the intrapulmonary shunt fraction reached its lowest value. In addition, a significant change of dynamic tidal respiratory compliance and oxygenation index was induced by PEEP titration. These results indicate that minimal VD/VT can be used for PEEP titration in ARDS.
\end{abstract}

\section{Introduction}

Acute respiratory distress syndrome (ARDS) is a severe and life-threatening medical condition that is common in critically

Correspondence to: Dr Wei Chen, Department of Critical Care Medicine, Beijing Shijitan Hospital, Capital Medical University, 10 Tieyi Road, Yangfangdian, Haidian, Beijing 100038, P.R. China E-mail: weichendr@163.com

Key words: acute respiratory distress syndrome, dead space fraction, positive end-expiratory pressure, recruitment maneuver ill patients and has a high mortality rate (1). It is a main reason for acute respiratory failure, and is characterized by widespread inflammation in the lungs $(1,2)$. ARDS can induce pathophysiological mechanisms of alveolar collapse, hyoxemia, vascular dysfunction and elevated dead space fraction [the ratio of dead space volume to tidal volume (VD/VT)] $(3,4)$.

Currently, the lung-protection strategy for ventilation involves the use of high positive end-expiratory pressure (PEEP) levels combined with low tidal volumes to prevent end expiratory alveolar collapse, increase functional residual capacity, reduce VD/VT and attenuate hypoxemia $(5,6)$. However, the application of higher levels of PEEP may not be necessarily beneficial, since it increases the inflation of lung regions. Additionally, it will also increase the risk of hemodynamic abnormalities as well as the lung injury induced by ventilation $(7,8)$. Numerous studies have attempted to define the optimal PEEP level on the basis of a variety of methods during a recruitment maneuver (RM) with decreasing PEEP (9-11).

A number of studies have applied the VD/VT method to assess the effects of lung recruitment and PEEP titration in patients with severe ARDS (9-11). VD/VT is a specific value based on the relatively high diffusibility of $\mathrm{CO}_{2}$ across tissue membranes (12), and the exchange of $\mathrm{CO}_{2}$ depends strictly on alveolar ventilation volume (13). However, some studies did not find a similar effect on VD/VT during PEEP titration $(14,15)$. Therefore, the application of the lowest VD/VT method to titrate the optimal PEEP in patients with ARDS remains to be investigated.

In the present study, an oleic acid lung-injury model in swine was used to evaluate the effect of varying the PEEP level on dead space fraction. The aim was to realize the changes in VD/VT induced by different PEEP levels in the ARDS swine model and to explore the feasibility of using the VD/VT ratio to guide the optimal PEEP titration.

\section{Materials and methods}

Animals and anesthesia. The study was a prospective, sham-controlled and in vivo animal study, and was approved by the animal ethics committee of Beijing Shijitan Hospital, affiliated to Capital Medical University (Beijing, China). 
Twelve healthy male swine (age, 11-13 months) with an average weight of $39.13 \pm 3.27 \mathrm{~kg}$ were provided by the animal center of Pinggu Hospital of Capital Medical University [licence: SYXK (B) 2010-0016]. The animals were housed at $21-27^{\circ} \mathrm{C}$ with a humidity of $45-55 \%$, with free access to food and water. Swine were fasted for $24 \mathrm{~h}$ and then were orotracheally intubated in the supine position during deep intramuscular anesthesia with ketamine ( $35 \mathrm{mg} / \mathrm{kg}$; Jiangsu Hengrui Medicine Co. Ltd., Lianyungang, China), $3 \%$ pentobarbital sodium (30 mg/kg; Sigma-Aldrich; Merck KGaA, Darmstadt, Germany) and diazepam (1.5 mg/kg; Sigma-Aldrich). A double cavity central venous catheter was inserted into the right internal jugular vein using the Seldinger technique (16) and connected to the monitoring system. Following line placement, the anesthetic was switched to total intravenous anesthesia with continuous infusion of pentobarbital sodium (2 $\mathrm{mg} / \mathrm{kg} / \mathrm{h}$ ), ketamine $(3 \mathrm{mg} / \mathrm{kg} / \mathrm{h})$ and pipecurium bromide (0.03 mg/kg/h; Gedeon Richter Plc., Budapest, Hungary). In all swine, a 4-French gauge arterial thermodilution catheter was inserted via the left femoral artery. The arterial catheter was connected to a computer for pulse contour analysis (Pulsion Medical Systems, Munich, Germany) for the clinical monitoring of hemodynamic measurements.

Monitoring. The respiration parameters of alveolar partial pressure of $\mathrm{O}_{2}\left(\mathrm{PAO}_{2}\right)$ /fraction of inspiration $\mathrm{O}_{2}\left(\mathrm{FiO}_{2}\right)$ ratio $(\mathrm{P} / \mathrm{F})$, arterial $\mathrm{CO}_{2}$ partial pressure $\left(\mathrm{PaCO}_{2}\right)$ and arterial $\mathrm{O}_{2}$ saturation $\left(\mathrm{SaO}_{2}\right)$ were directly measured through arterial blood gas analysis using the (GEM Premier 3000; Instrumentation Laboratory, Inc., Lexington MA, USA) (17). Lung maximum dynamic tidal respiratory compliance (Cdyn) was monitored using a SERVI-i ventilator (Siemens Maquet Critical Care AB, Slona, Sweden).

The VD/VT ratio was measured via the single-breath analysis of $\mathrm{CO}_{2}$ (18) (NICO Cardiopulmonary Management System; Novametrix; Philips Respironics, Murrysville, PA, USA). With this method, the partial pressure of mixed-expired $\mathrm{CO}_{2}$ was calculated followed by the Enghoff modification of the Bohr equation as follows: VD/VT $=\left(\mathrm{PaCO}_{2}-\mathrm{PeCO}_{2}\right) / \mathrm{PaCO}_{2}$, where $\mathrm{PeCO}_{2}$ represents mixed expired $\mathrm{CO}_{2}$ (19). An arterial blood gas sample was obtained when the $\mathrm{PeCO}_{2}$ variability on the NICO monitor was $\leq 1 \mathrm{mmHg}$ within $5 \mathrm{~min}$. The NICO sensor fitted between the Y-piece and the endotracheal tube.

The intrapulmonary shunt fraction (Qs/Qt) was calculated according to the standard formulae:

$$
\begin{aligned}
& \mathrm{Qs} / \mathrm{Qt}=\left(\mathrm{CcO}_{2}-\mathrm{CaO}_{2}\right) /\left(\mathrm{CcO}_{2}-\mathrm{CvO}_{2}\right) \\
& \mathrm{CaO}_{2}=\mathrm{Hb} \times \mathrm{SaO}_{2} \times 1.34+\mathrm{PAO}_{2} \times 0.0031 \\
& \mathrm{CvO}_{2}=\mathrm{Hb} \times \mathrm{SvO}_{2} \times 1.34+\mathrm{PvO}_{2} \times 0.0031 \\
& \mathrm{CcO}_{2}=\mathrm{Hb} \times \mathrm{ScO}_{2} \times 1.34+\mathrm{PcO}_{2} \times 0.0031 \\
& \mathrm{ScO}_{2} \approx 100 \% \\
& \mathrm{PcO}_{2} \approx \mathrm{PAO}_{2} \\
& \mathrm{PAO}_{2}=\mathrm{PiO}_{2}-\mathrm{PaCO}_{2} / \mathrm{R} \\
& \mathrm{PiO}_{2}=\left(\mathrm{PB}-\mathrm{PH}_{2} \mathrm{O}\right) \times \mathrm{FiO}_{2}
\end{aligned}
$$

where Qs represents shunted pulmonary blood flow; Qt represents total pulmonary blood flow; $\mathrm{CcO}_{2}$ represents pulmonary capillary $\mathrm{O}_{2}$ content; $\mathrm{PvO} 2$ represents mixed venous $\mathrm{O} 2$ partial pressure; $\mathrm{CaO}_{2}$ represents arterial $\mathrm{O}_{2}$ content; $\mathrm{CvO}_{2}$ represents mixed venous $\mathrm{O}_{2}$ content; $\mathrm{Hb}$ represents hemoglobin;
$\mathrm{PiO}_{2}$ represents partial pressure of inspired $\mathrm{O}_{2}$; $\mathrm{R}$ represents respiratory quotient (0.8); $\mathrm{PB}$ represents barometric pressure ( $\sim 100 \mathrm{kPa}$ on sea level); $\mathrm{PH}_{2} \mathrm{O}$ represents saturation vapor pressure $\left(6.3 \mathrm{kPa}\right.$ at $\left.37^{\circ} \mathrm{C}\right)$.

The hemodynamic parameters of cardiac output index (CI), global end-diastolic volume index (GEDI), extravascular lung water index (ELWI), intra-thoracic blood volume index (ITBI) and systemic vascular resistance index (SVRI) were directly measured by the thermodilution method (20) using the PICCO system (Pulsion Medical Systems). The central venous pressure (CVP) was monitored with the central venous catheter in the right internal jugular vein.

Protocol. Following intubation, lungs were ventilated in a volume-controlled ventilation mode, with the following initial parameters: VT of $8 \mathrm{ml} / \mathrm{kg}, \mathrm{FiO}_{2}$ of 1.0, PEEP of $5 \mathrm{~cm} \mathrm{H}_{2} \mathrm{O}$, respiratory rate of 40 breaths/min, and inspiratory to expiratory time ratio (I:E) of 1:2. These settings were maintained for $30 \mathrm{~min}$ to achieve stabilization.

ARDS induction. After recording pre-injury hemodynamic, gas exchange, respiratory mechanics measurements and oxygen metabolism, $0.2 \mathrm{ml} / \mathrm{kg}$ oleic acid (Sigma-Aldrich) in $40 \mathrm{ml}$ saline was slowly (within $15 \mathrm{~min}$ ) injected in the right atrium via the central venous catheter. After a 90-min injury stabilization period, the experimental protocol was initiated. A successful model of ARDS was defined by $\mathrm{P} / \mathrm{F}<200 \mathrm{mmHg}$ for $90 \mathrm{~min}$ following oleic acid infusion (21). Each swine was infused continuously with intravenous saline at a rate of $100 \mathrm{ml} / \mathrm{h}$.

Lung recruitment maneuver. The swine were stabilized for $15 \mathrm{~min}$ on the following ventilator settings and followed by data gathering: Pressure control ventilation $(\mathrm{PCV})$ peak pressure, $35 \mathrm{~cm} \mathrm{H}{ }_{2} \mathrm{O}$; PEEP, $20 \mathrm{~cm} \mathrm{H}_{2} \mathrm{O}$; inspiratory time, $0.6 \mathrm{sec}$; rate, 40/min and $\mathrm{FiO}_{2}$ 1.0. The PEEP was then set to $20 \mathrm{~cm} \mathrm{H}_{2} \mathrm{O}$ and pressure control set to a peak airway pressure of $40 \mathrm{~cm} \mathrm{H}_{2} \mathrm{O}$. These settings were maintained for $2 \mathrm{~min}$, followed by a 15-min stabilization period with a peak pressure $35 \mathrm{~cm} \mathrm{H}_{2} \mathrm{O}$. Data were gathered if $\mathrm{PAO}_{2}+\mathrm{PaCO}_{2}$ was $>400 \mathrm{mmHg}$. If $\mathrm{PAO}_{2}+\mathrm{PaCO}_{2}$ was $<400 \mathrm{mmHg}$, the PEEP setting remained unchanged and pressure control was increased to obtain a peak airway pressure of $45 \mathrm{~cm} \mathrm{H}_{2} \mathrm{O}$. This pattern was sustained for $2 \mathrm{~min}$, followed by a 15 -min stabilization period with peak pressure $35 \mathrm{~cm} \mathrm{H}_{2} \mathrm{O}$. If $\mathrm{PAO}_{2}+\mathrm{PaCO}_{2}$ was $>400 \mathrm{mmHg}$, the lung recruitment was considered complete $(22,23)$.

PEEP titration. When the sum of $\mathrm{PAO}_{2}$ and $\mathrm{PaCO}_{2}$ was $>400 \mathrm{mmHg}$, all swine underwent a decremental PEEP titration in volume control mode. PEEP was decreased in $2 \mathrm{~cm} \mathrm{H}_{2} \mathrm{O}$ steps (from 20 to $0 \mathrm{~cm} \mathrm{H}_{2} \mathrm{O}$ ) and was maintained at each level for $10 \mathrm{~min}$. Cdyn was measured at each step using a VT of $8 \mathrm{ml} / \mathrm{kg}$ and a frequency of 40/min. Additionally, the physiological data including Cdyn, VD/VT and P/F were gathered following each step. The optimal open-lung PEEP was identified by the lowest VD/VT method, which was achieved as determined by a reduction in VD/VT and then a rise with each PEEP step.

The study consisted of the following seven experimental periods: i) Pre-injury period, which involved introduction of catheters and mechanical ventilation using the initial parameters; ii) injury period, when ARDS was induced by the 
intravenous administration of oleic acid; iii) PEEP period 1 (Po-4), $4 \mathrm{~cm} \mathrm{H}_{2} \mathrm{O}$ below the optimal PEEP; iv) PEEP period 2 (Po-2), $2 \mathrm{~cm} \mathrm{H}_{2} \mathrm{O}$ below the optimal PEEP; v) PEEP period 3 (Po), optimal PEEP; vi) PEEP period 4 ( $\mathrm{Po}+2), 2 \mathrm{~cm} \mathrm{H}_{2} \mathrm{O}$ above the optimal PEEP; vii) PEEP period 5 ( $\mathrm{Po}+4) .4 \mathrm{~cm} \mathrm{H}_{2} \mathrm{O}$ above the optimal PEEP.

Statistical analysis. All data were analyzed using IBM-SPSS version 19.0 statistics software (IBM SPSS, Armonk, NY, USA) and were expressed as mean \pm standard deviation. Analysis of non-parametric repeated-measures ANOVA test was used for comparison of all variables collected during the seven assessment periods. $\mathrm{P}<0.05$ was considered to indicate a statistically significant difference.

\section{Results}

Optimal PEEP. The optimal PEEP identified by the lowest $\mathrm{VD} / \mathrm{VT}$ method was $13.25 \pm 1.36 \mathrm{~cm} \mathrm{H}_{2} \mathrm{O}$.

$V D / V T$ changes induced by different PEEP levels. There was a significant $(\mathrm{P}<0.05)$ increase in VD/VT from the pre-injury period $(0.35 \pm 0.11)$ to the injury period $(0.68 \pm 0.10)$. Following the RM, VD/VT decreased to the lowest value of $0.44 \pm 0.08$ (vs. injury, $\mathrm{P}<0.05$ ) at the optimal PEEP. When PEEP decreased to Po- $4 \mathrm{~cm} \mathrm{H}_{2} \mathrm{O}$, VD/VT significantly increased to $0.60 \pm 0.07$ $(\mathrm{P}<0.05)$. However, at the $\mathrm{Po}+4 \mathrm{~cm} \mathrm{H}_{2} \mathrm{O}, \mathrm{VD} / \mathrm{VT}$ was higher $(0.64 \pm 0.10$; Fig. 1 and Table I).

Changes of P/F during PEEP decrement. There was a statistically significant $(\mathrm{P}<0.05)$ reduction in $\mathrm{P} / \mathrm{F}$ from the pre-injury period $(562 \pm 162 \mathrm{mmHg})$ to the injury period $(75 \pm 21 \mathrm{mmHg})$. Following the RM, P/F values significantly increased from $166 \pm 109$ to $365 \pm 133 \mathrm{mmHg}$ when the PEEP increased from the Po- $4 \mathrm{~cm} \mathrm{H}_{2} \mathrm{O}$ to $\mathrm{Po}+2 \mathrm{~cm} \mathrm{H}_{2} \mathrm{O}$. However, P/F decreased again at $\mathrm{Po}+4 \mathrm{~cm} \mathrm{H}_{2} \mathrm{O}$ (Fig. 2 and Table I).

Changes of Cdyn and Qs/Qt during PEEP decrement. At all periods after injury, the Cdyn values were decreased compared with the pre-injury value $(\mathrm{P}<0.05)$, but the highest post-RM values were observed at the pressure level of optimal PEEP. However, Qs/Qt values were significantly $(\mathrm{P}<0.05)$ lower at the pressure level of optimal PEEP compared with the levels at the injury period (Figs. 3 and 4 and Table I).

Hemodynamic changes induced by different PEEP levels. The CI, ITBI, GEDI and SVRI did not change significantly during the pre-injury, injury and variable PEEP periods, although a downtrend was observed in CI with the increase of PEEP. For CVP, a significant $(\mathrm{P}<0.05)$ increment was observed during the variable PEEP period relative to the pre-injury and injury period. In addition, CVP increased markedly as PEEP increased. In comparison with the pre-injury period, EVLWI values were significantly higher during the injury and variable PEEP periods $(\mathrm{P}<0.05$; Table II $)$.

\section{Discussion}

Currently, many methods exist in the literature for identifying the PEEP to set in patients with ARDS following a lung RM.

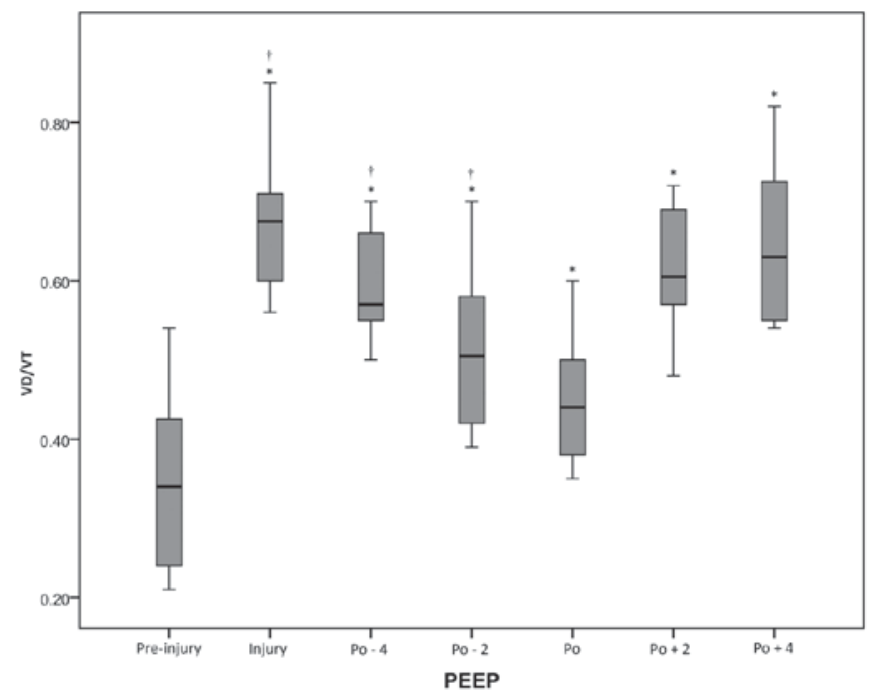

Figure 1. VD/VT of the acute respiratory distress syndrome swine model under different conditions. ${ }^{*} \mathrm{P}<0.05$ vs. pre-injury; ${ }^{\dagger} \mathrm{P}<0.05$ vs. injury. VD/VT, ratio of dead space volume to tidal volume (dead space fraction); PEEP, positive end-expiratory pressure; Po, optimal PEEP; -n, n cm Hg below Po; +n; $\mathrm{n} \mathrm{cm} \mathrm{Hg}$ above Po.

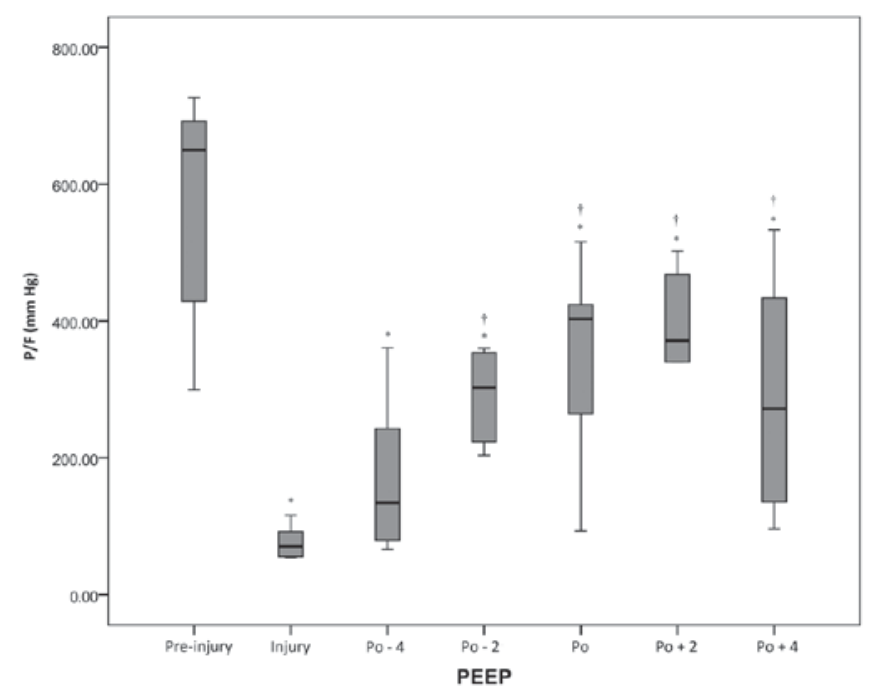

Figure 2. P/F ratio of the acute respiratory distress syndrome swine model under different conditions. ${ }^{*} \mathrm{P}<0.05$ vs. pre-injury; ${ }^{\dagger} \mathrm{P}<0.05$ vs. injury. $\mathrm{P} / \mathrm{F}$, alveolar partial pressure of oxygen/fraction of inspiration oxygen (oxygenation index); PEEP, positive end-expiratory pressure; Po, optimal PEEP; -n, $\mathrm{n} \mathrm{cm} \mathrm{Hg}$ below Po; +n; $\mathrm{n} \mathrm{cm} \mathrm{Hg} \mathrm{above} \mathrm{Po.}$

The detection parameters include Cdyn, $\mathrm{PAO}_{2}$, maximum $\mathrm{PAO}_{2}+\mathrm{PaCO}_{2}$, as well as the inflation lower inflection point (Pflex) and deflation upper Pflex on the pressure-volume curve (22). However, controversy over the approach for setting PEEP has existed since 1967 when Ashbaugh et al (24) first used PEEP to manage ARDS. A previous study has reported that an increased VD/VT ratio is one of the markers of early ARDS, and furthermore, an elevated VD/VT ratio is associated with an increased risk of mortality (10). In the present study, a decremental PEEP procedure was performed following an RM in swine with ARDS. It was observed that PEEP caused significant changes of VD/VT, Qs/Qt, Cdyn and P/F. The results indicated that in cases of recruitment maneuver and 

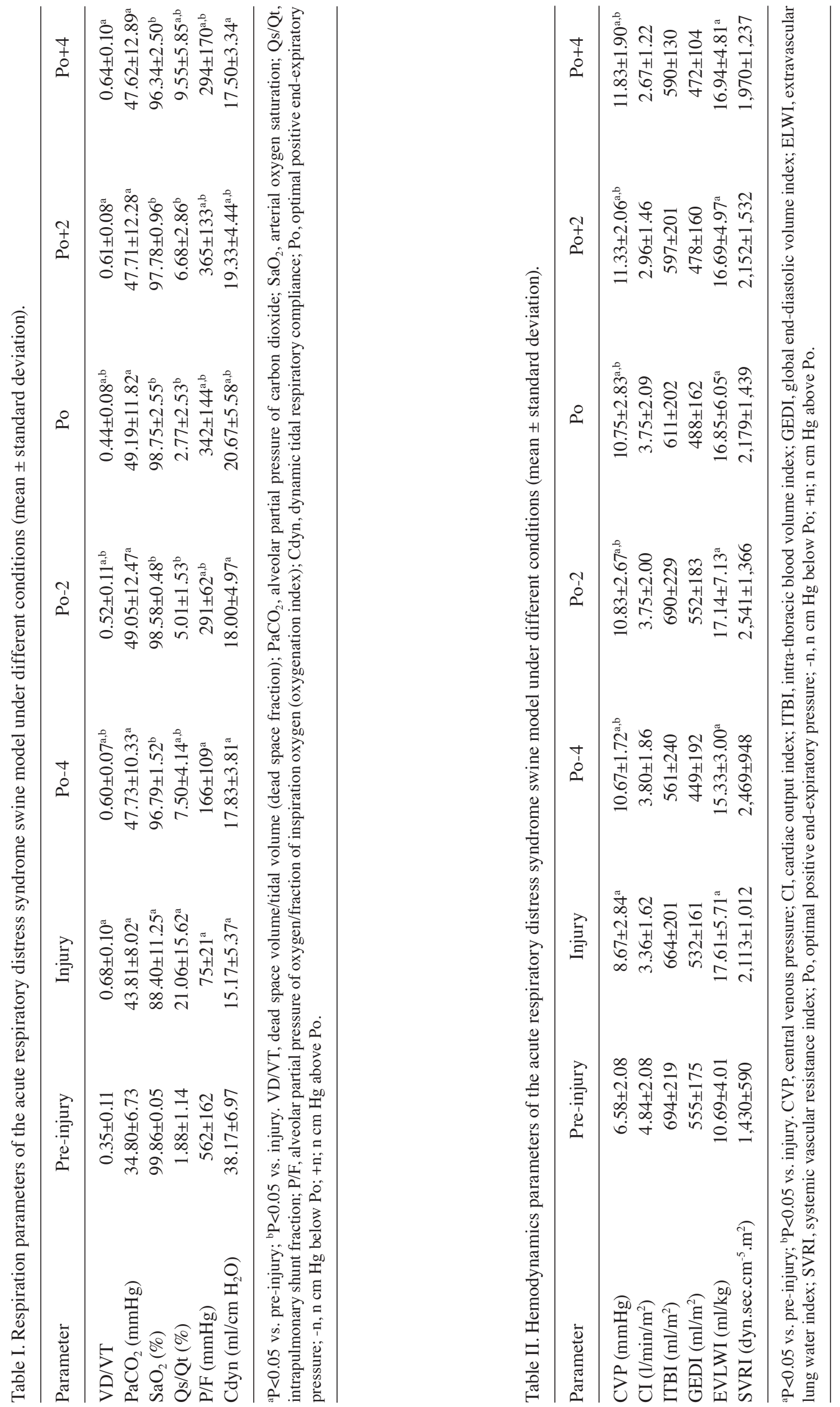


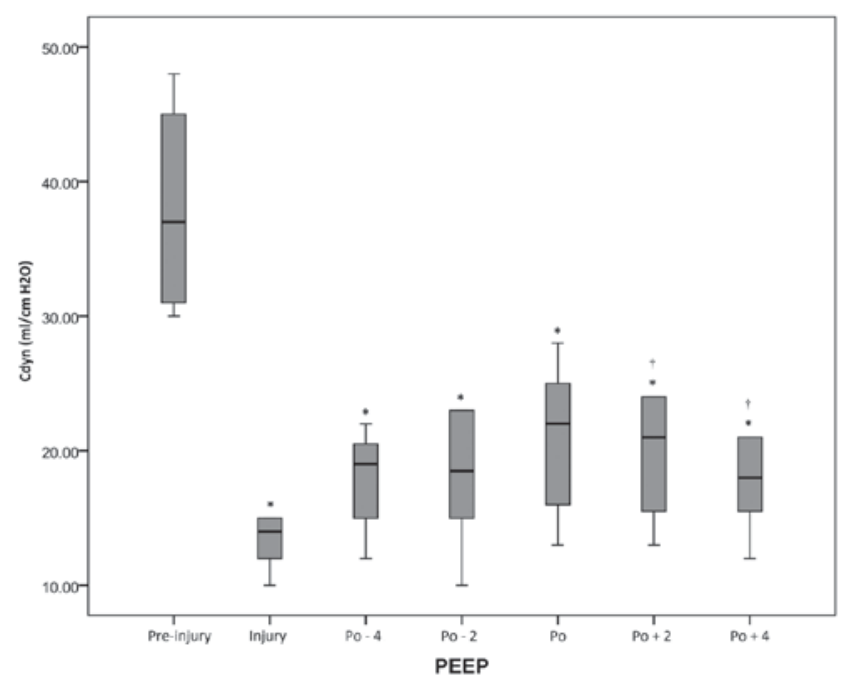

Figure 3. Cdyn of the acute respiratory distress syndrome swine model under different conditions. ${ }^{*} \mathrm{P}<0.05$ vs. pre-injury; ${ }^{\dagger} \mathrm{P}<0.05$ vs. injury. Cdyn, dynamic tidal respiratory compliance; PEEP, positive end-expiratory pressure; Po, optimal PEEP; -n, $\mathrm{n}$ cm Hg below Po; +n; n cm Hg above Po.

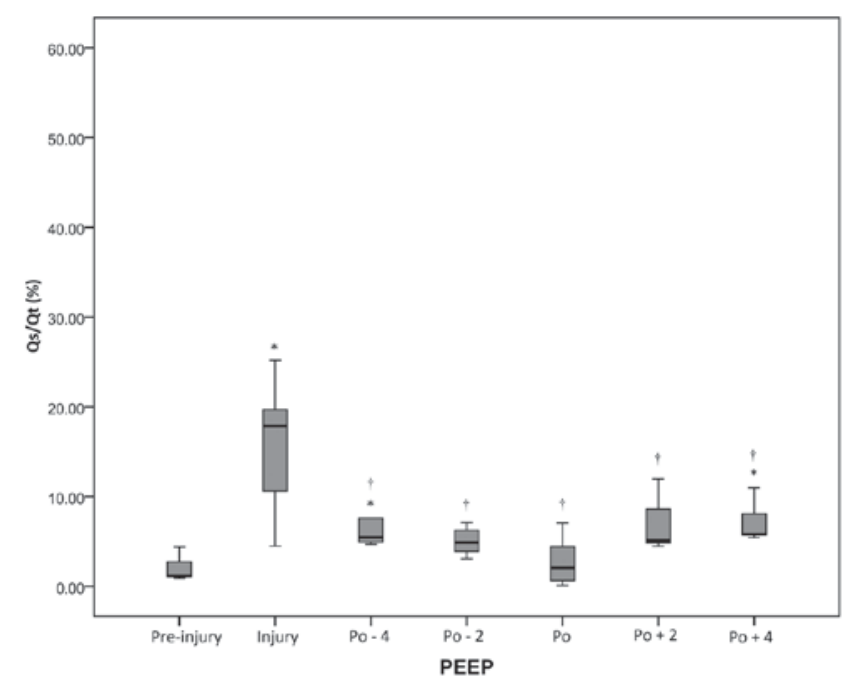

Figure 4. Qs/Qt of the acute respiratory distress syndrome swine model under different conditions. " $\mathrm{P}<0.05$ vs. pre-injury; ${ }^{\top} \mathrm{P}<0.05$ vs. injury. $\mathrm{Q} / \mathrm{Qt}$, intrapulmonary shunt ratio; PEEP, positive end-expiratory pressure; Po, optimal PEEP; - $\mathrm{n}, \mathrm{n} \mathrm{cm} \mathrm{Hg}$ below Po; $+\mathrm{n} ; \mathrm{n} \mathrm{cm} \mathrm{Hg}$ above Po.

a PEEP titration procedure, VD/VT might become a clinically useful tool for assessing collapsed alveolar opening and titrating the optimal PEEP in ARDS.

A markedly elevated VD/VT may be detected in early ARDS, which is suggested to be due to the obstruction of pulmonary blood flow in the extra-alveolar pulmonary circulation (25), and increasing areas with a low ventilation (26). Importantly, injury of pulmonary capillaries by inflammation and thrombus can also result in increased VD/VT $(27,28)$. As shown in Fig. 1, VD/VT was significantly higher during the injury period than during the pre-injury period, which was in accordance with results from previous studies $(29,30)$. In addition, the results showed that different PEEP levels following RM caused significant changes in VD/VT, which was in agreement with the findings of Maisch et al (31), who showed that different PEEP levels after RM caused significant changes in VD/VT and P/F, as well as compliance in patients with ARDS. With the increase of PEEP, VD/VT showed a trend of decline. However, higher PEEP may lead to an increase of the VD/VT ratio, which might be caused by the regional over-distention of well-ventilated alveoli (26) or by a reduction in cardiac output (32). As can be seen from the formula used to calculate $\mathrm{VD} / \mathrm{VT}, \mathrm{VD} / \mathrm{VT}$ is inversely related to $\mathrm{CO}_{2}$ elimination. The elimination of $\mathrm{CO}_{2}$ by the lung is influenced by effective alveolar surface area, alveolar ventilation and cardiac output $(33,34)$. Following the RM and optimal PEEP, the $\mathrm{CO}_{2}$ elimination capacity of the lung is increased, because alveolar ventilation is markedly increased. The present study also showed that in the PEEP levels ranging from Po-4 to Po, VD/VT was gradually reduced. However, when the PEEP levels ranged from $\mathrm{Po}+2$ to $\mathrm{Po}+4 \mathrm{~cm} \mathrm{H}_{2} \mathrm{O}$, $\mathrm{VD} / \mathrm{VT}$ increased again. A previous study demonstrated that VD was significantly increased in piglets with higher PEEP ( $20 \mathrm{~cm} \mathrm{H}_{2} \mathrm{O}$ ), which was induced by hyperinflation of the lung region (35).

In ARDS, the alveolar collapse causes a deficiency of alveolar ventilation while the blood flow does not significantly decrease and VD/VT increases, which leads to a decline of the ventilation and blood flow and increase of Qs/Qt. In the present study, the Qs/Qt ratio achieved its maximum value with the increase of VD/VT in ARDS conditions. Under the application of PEEP, the Qs/Qt ratio showed a trend of decline to approach the base value with the reduction of $\mathrm{VD} / \mathrm{VT}$. Furthermore, Qs/Qt reached its minimum under the optimal PEEP state.

Higher PEEP increases VD/VT via a reduction in cardiac output $(32,36)$. In the present study, following the application of PEEP, CVP increased as the PEEP increased, indicating that PEEP significantly affected the loading conditions of the right atrium to reduce the volume of returned blood. The increase of CVP might be due to the augmentation of intrapleural pressure and vena cava reflux resistance that were induced by the high PEEP levels. Moreover, the reduction of returned blood volume gives rise to a reduction of left atrium cardiac output, which is in accordance with the present study's findings that the CI gradually declined with the increase of PEEP. Notably, $\mathrm{CI}$ had no evident significant difference among PEEP states, because the PEEP range in this study was $<20 \mathrm{~cm} \mathrm{H}_{2} \mathrm{O}$.

In conclusion, measurement of $\mathrm{VD} / \mathrm{VT}$ is valuable in assessing the effects of lung recruitment. The minimal VD/VT can be used as one of many options for the assessment of PEEP titration in ARDS. In the context of RM and a PEEP titration procedure, a reduction in $\mathrm{VD} / \mathrm{VT}$ and $\mathrm{Qs} / \mathrm{Qt}$, and an increase in Cdyn and P/F indicate a maximum amount of effectively expanded alveoli. The VD/VT may be prospectively used in future clinical trials, particularly when the goal is to evaluate the benefit of an open-lung protective ventilation strategy in patients with ARDS.

However, there are certain limitations to the present study. In the context of RM and PEEP, alveolar ventilation volume could not be assessed by direct computed tomography methods. In addition, PEEP was not evaluated at $>20 \mathrm{~cm} \mathrm{H}_{2} \mathrm{O}$ after RM in the ARDS model, so it is impossible to comment on the effect of higher PEEP on VD/VT and Qs/Qt under those circumstances. Finally, the sample size of 12 swine 
is relatively small, and arguably underpowered to detect an important effect.

\section{Acknowledgements}

This study was supported by a grant from the National Natural Science Foundation of China (grant no. 81372043).

\section{References}

1. Phua J, Badia JR, Adhikari NK, Friedrich JO, Fowler RA, Singh JM, Scales DC, Stather DR, Li A, Jones A, et al: Has mortality from acute respiratory distress syndrome decreased over time? A systematic review. Am J Respir Crit Care Med 179: 220-227, 2009.

2. Petty TL: Acute respiratory distress syndrome (ARDS). Dis Mon 36: 1-58, 1990

3. Villar J, Blanco J, Añón JM, Santos-Bouza A, Blanch L, Ambrós A, Gandía F, Carriedo D, Mosteiro F, Basaldúa S, et al: The ALIEN study: Incidence and outcome of acute respiratory distress syndrome in the era of lung protective ventilation. Intensive Care Med 37: 1932-1941, 2011.

4. Bull TM, Clark B, McFann K and Moss M; National Institutes of Health/National Heart, Lung, and Blood Institute ARDS Network: Pulmonary vascular dysfunction is associated with poor outcomes in patients with acute lung injury. Am J Respir Crit Care Med 182: 1123-1128, 2010.

5. Lachmann B: Open up the lung and keep the lung open. Intensive Care Med 18: 319-321, 1992.

6. Amato MB, Barbas CS, Medeiros DM, Magaldi RB, Schettino GP, Lorenzi-Filho G, Kairalla RA, Deheinzelin D, Munoz C, Oliveira R, et al: Effect of a protective-ventilation strategy on mortality in the acute respiratory distress syndrome. N Engl J Med 338: 347-354, 1998.

7. Levy MM: PEEP in ARDS-how much is enough? $\mathrm{N}$ Engl J Med 351: 389-391, 2004.

8. Sakuramoto H, Shimojo N, Jesmin S, Unoki T, Kamiyama J, Oki M, Miya K, Kawano S and Mizutani T: Repeated open endotracheal suctioning causes gradual desaturation but does not exacerbate lung injury compared to closed endotracheal suctioning in a rabbit model of ARDS. BMC Anesthesiol 13: 47, 2013.

9. Charron C, Repesse X, Bouferrache K, Bodson L, Castro S, Page B, Jardin F and Vieillard-Baron A: $\mathrm{PaCO}_{2}$ and alveolar dead space are more relevant than $\mathrm{PaO}_{2} / \mathrm{FiO}_{2}$ ratio in monitoring the respiratory response to prone position in ARDS patients: A physiological study. Crit Care 15: R175, 2011.

10. Fengmei G, Jin C, Songqiao L, Congshan Y and Yi Y: Dead space fraction changes during PEEP titration following lung recruitment in patients with ARDS. Respir Care 57: 1578-1585, 2012.

11. Gattinoni L, Caironi P, Cressoni M, Chiumello D, Ranieri VM, Quintel M, Russo S, Patroniti N, Cornejo R and Bugedo G: Lung recruitment in patients with the acute respiratory distress syndrome. N Engl J Med 354: 1775-1786, 2006.

12. Tusman G, Suarez-Sipmann F, Böhm SH, Pech T, Reissmann H, Meschino G, Scandurra A and Hedenstierna G: Monitoring dead space during recruitment and PEEP titration in an experimental model. Intensive Care Med 32: 1863-1871, 2006.

13. Uttman L, Bitzén U, De Robertis E, Enoksson J, Johansson L and Jonson B: Protective ventilation in experimental acute respiratory distress syndrome after ventilator-induced lung injury: A randomized controlled trial. Br J Anaesth 109: 584-594, 2012.

14. Beydon L, Uttman L, Rawal R and Jonson B: Effects of positive end-expiratory pressure on dead space and its partitions in acute lung injury. Intensive Care Med 28: 1239-1245, 2002.

15. Blanch L, Lucangelo U, Lopez-Aguilar J, Fernandez R and Romero P: Volumetric capnography in patients with acute lung injury: Effects of positive end-expiratory pressure. Eur Respir J 13: 1048-1054, 1999.
16. Higgs Z, Macafee D, Braithwaite B and Maxwell-Armstrong C: The Seldinger technique: 50 years on. Lancet 366: 1407-1409, 2005.

17. Marshall W: Arterial blood gas analysis. Ann Clin Biochem 47: 283-283, 2010

18. Fletcher R, Jonson B, Cumming G and Brew J: The concept of deadspace with special reference to the single breath test for carbon dioxide. Br J Anaesth 53: 77-88, 1981.

19. Fowler WS: Lung function studies; The respiratory dead space. Am J Physiol 154: 405-416, 1948.

20. Hofer CK, Furrer L, Matter-Ensner S, Maloigne M, Klaghofer R, Genoni M and Zollinger A: Volumetric preload measurement by thermodilution: A comparison with transoesophageal echocardiography. Br J Anaesth 94: 748-755, 2005.

21. Quintel M, Pelosi P, Caironi P, Meinhardt JP, Luecke T, Herrmann P, Taccone P, Rylander C, Valenza F, Carlesso E and Gattinoni L: An increase of abdominal pressure increases pulmonary edema in oleic acid-induced lung injury. Am J Respir Crit Care Med 169: 534-541, 2004.

22. Caramez MP, Kacmarek RM, Helmy M, Miyoshi E, Malhotra A, Amato MB and Harris RS: A comparison of methods to identify open-lung PEEP. Intensive Care Med 35: 740-747, 2009.

23. Borges JB, Okamoto VN, Matos GF, Caramez MP, Arantes PR, Barros F, Souza CE, Victorino JA, Kacmarek RM, Barbas CS, et al: Reversibility of lung collapse and hypoxemia in early acute respiratory distress syndrome. Am J Respir Crit Care Med 174: 268-278, 2006.

24. Ashbaugh DG, Bigelow DB, Petty TL and Levine BE: Acute respiratory distress in adults. Lancet 2: 319-323, 1967.

25. Greene R, Zapol WM, Snider MT, Reid L, Snow R, O'Connell RS and Novelline RA: Early bedside detection of pulmonary vascular occlusion during acute respiratory failure. Am Rev Respir Dis 124: 593-601, 1981.

26. Dantzker DR, Brook CJ, Dehart P, Lynch JP and Weg JG: Ventilation-perfusion distributions in the adult respiratory distress syndrome. Am Rev Respir Dis 120: 1039-1052, 1979.

27. Idell S, Mazar AP, Bitterman P, Mohla S and Harabin AL: Fibrin turnover in lung inflammation and neoplasia. Am J Respir Crit Care Med 163: 578-584, 2001.

28. Tomashefski JF Jr, Davies P, Boggis C, Greene R, Zapol WM and Reid LM: The pulmonary vascular lesions of the adult respiratory distress syndrome. Am J Pathol 112: 112-126, 1983.

29. Nuckton TJ, Alonso JA, Kallet RH, Daniel BM, Pittet JF, Eisner MD and Matthay MA: Pulmonary dead-space fraction as a risk factor for death in the acute respiratory distress syndrome. N Engl J Med 346: 1281-1286, 2002.

30. Lucangelo U, Bernabè F, Vatua S, Degrassi G, Villagrà A, Fernandez R, Romero PV, Saura P, Borelli M and Blanch L: Prognostic value of different dead space indices in mechanically ventilated patients with acute lung injury and ARDS. Chest 133: 62-71, 2008.

31. Maisch S, Reissmann H, Fuellekrug B, Weismann D, Rutkowski T, Tusman G and Bohm SH: Compliance and dead space fraction indicate an optimal level of positive end-expiratory pressure after recruitment in anesthetized patients. Anaesth Analg 106: 175-181, 2008

32. Coffey RL, Albert RK and Robertson HT: Mechanisms of physiological dead space response to PEEP after acute oleic acid lung injury. J Appl Physiol Respir Environ Exerc Physiol 55: $1550-1557,1983$.

33. Breen PH and Mazumdar B: How does positive end-expiratory pressure decrease $\mathrm{CO}_{2}$ elimination from the lung? Respir Physiol 103: 233-242, 1996.

34. Anderson CT and Breen PH: Carbon dioxide kinetics and capnography during critical care. Crit Care 4: 207-215, 2000.

35. Tang R, Huang Y, Chen Q, Hui X, Li Y, Yu Q, Zhao H, Yang Y and Qiu H: The effect of alveolar dead space on the measurement of end-expiratory lung volume by modified nitrogen wash-out/wash-in in lavage-induced lung injury. Respir Care 57: 2074-2081, 2012.

36. Suwa K, Hedley-Whyte J and Bendixen HH: Circulation and physiologic dead space changes on controlling the ventilation of dogs. J Appl Physiol 21: 1855-1859, 1966. 